Original Research Article

\title{
Evaluate use of over the counter drugs among medical students in a tertiary care teaching hospital
}

\author{
Megha Sood*, Jagminder Kaur Bajaj, Nipunjot Grewal
}

Department of Pharmacology, Punjab Institute of Medical Sciences, Jalandhar, Punjab, India

Received: 20 February 2019 Accepted: 30 March 2019

\section{*Correspondence to:}

Dr. Megha Sood,

Email: msood11@gmail.com

Copyright: (C) the author(s), publisher and licensee Medip Academy. This is an openaccess article distributed under the terms of the Creative Commons Attribution NonCommercial License, which permits unrestricted noncommercial use, distribution, and reproduction in any medium, provided the original work is properly cited.

\begin{abstract}
Background: In our country there is easy availability of drugs over the counter leading to their unintentional misuse and abuse. Over the counter availability of drugs does offer the benefit of easy access to medicines and allows individuals to become in charge of their own health. It is important to understand that medical education can impact the OTC drug use amongst medical students. In order to observe the pattern of OTC drug use among the first and second professional MBBS students we planned this study. The aim of the study was to evaluate use of over the counter (OTC) drugs among medical students in a tertiary care teaching hospital.

Methods: Our study was a cross sectional study conducted on first and second professional MBBS students. Authors administered a self structured, prevalidated questionnaire to the students. The data obtained was tabulated, analyzed and the results calculated in percentages.

Results: The use of OTC drugs is common amongst undergraduate students. All $(100 \%)$ the students who participated in the study had used OTC drugs at some point in their life. The common conditions prompting use of OTC drugs include head ache, body aches (74\%), fever (72\%), respiratory conditions such as: cold $(60 \%)$, cough $(28.5 \%)$, abdominal symptoms such as: abdominal pain $(14 \%)$, gastritis $(7.5 \%)$, diarrhea $(6 \%)$, vomiting $(5 \%)$ and allergies $(10 \%)$. Very few students reported adverse drug reactions with these drugs.

Conclusions: From our study we have concluded that OTC drugs are commonly used amongst medical students. So, periodic training and talks on self medication are necessary for them. Student knowledge in this aspect will help them in future counseling of their patients.
\end{abstract}

Keywords: Analgesics, Adverse drug reactions, Over the counter, Prescription

\section{INTRODUCTION}

Over the counter medications are the ones that a person can buy without a prescription and are considered safe and effective for general population. Over the counter availability of drugs allows individuals to become in charge of their own health and decreases burden on the health care system, allowing physicians to focus on seriously ill patients. ${ }^{1}$ With lesser number of individuals seeking professional help, the health care costs also come down. But at the same time, self medication is fraught with risk of increased incidence of adverse drug reactions, drugdrug interactions and delayed diagnosis of severe illnesses. With increasing number of prescription medicines being switched to over the counter medications it seems necessary to counsel people on the safe use of drugs, as many individuals may lack health care literacy necessary for self medication. ${ }^{2,3}$

In our country there is easy availability of drugs over the counter leading to their unintentional misuse and abuse. Policy makers, doctors, pharmacists and consumers play a 
part in this. ${ }^{4}$ Example: Availability of antimicrobials without prescription results in irrational use, culminating in masking of infections and antibiotic resistance. ${ }^{5}$ Similarly use of over the counter pain medication can result in adverse effects like epigastric pain, dyspepsia and hypersensitivity reactions. ${ }^{6}$ Accidental overdose with drugs such as acetaminophen can end up in acute liver failure which is the most common cause of acute liver failure in adults. ${ }^{7}$

Keeping the above points in consideration, regulations restricting the availability need to be balanced with access to the segment of population where health care facilities and availability of doctors is limited.

Self medication is common among doctors. Undergraduate medical students have access to information on various medicines and hence it is important to understand the pattern of use of over the counter drugs in them. Keeping these aspects in mind we planned to study the pattern of over the counter drug use among the first and second professional MBBS students. The study was planned to see if medical knowledge early on in their career influence their choice of medication and pattern of use.

\section{METHODS}

The study was approved by the Institutional Ethics Committee and was carried on students of first and second prof who consented to be part of the study. This was a cross sectional study where we administered a self structured, prevalidated questionnaire to the students. The questionnaire included a total of nine questions of which five were close ended and four open ended. The open ended questions were included to allow respondents to share more information regarding their use of OTC drugs. The questionnaire covered various aspects of OTC drug usage which included common illnesses prompting the use, methods of obtaining OTC drugs, reasons cited for practicing self medication, awareness of dosage and ADRs with these drugs. The questionnaire was validated by $3 \mathrm{rd}$ year MBBS students who were not part of the study. The participating students were familiarized with the term 'Over the counter drugs' before carrying on the study. The students who were absent and those who returned incompletely filled questionnaire were excluded from the study.

\section{Statistical analysis}

The data was tabulated, analyzed and the results were calculated in percentages.

\section{RESULTS}

A total of 200 students responded to the questionnaire. All $(100 \%)$ the students who participated in the study have used OTC drugs at some point in their life. The common conditions prompting use of OTC drugs include head ache, body aches (74\%), fever (72\%), Respiratory conditions such as: cold (60\%), cough $(28.5 \%)$, abdominal symptoms such as: abdominal pain (14\%), gastritis $(7.5 \%)$, diarrhea $(6 \%)$, vomiting $(5 \%)$ and allergies (10\%) (Figure 1).

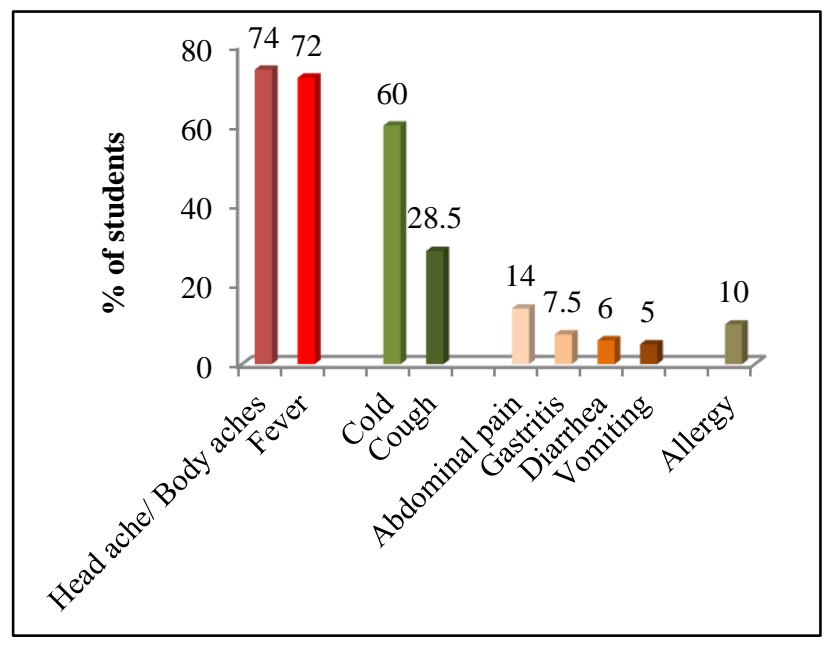

Figure 1: Indications for using OTC drugs.

This makes the use of analgesics, antipyretics, antihistaminics, antacids and antiemetics common amongst the medical students.

In present study $58 \%$ of the students were confident that they were taking correct medicine for their ailment. $38 \%$ stated that the reason behind self medication is lack of time to visit a doctor. Financial constraint was not a major issue in medical students as only (4\%) cited this as the reason for not seeking proper prescription from a doctor.

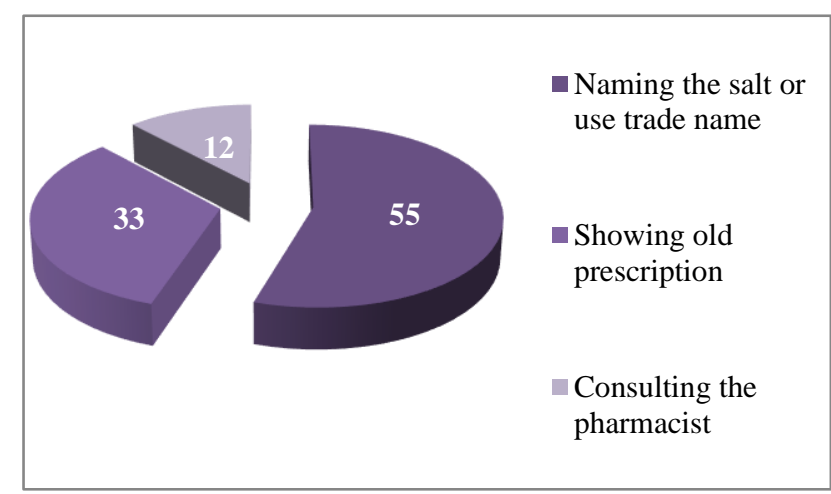

Figure 2: Methods used to obtain over the counter drugs.

Total $55 \%$ of the students used the name of the active ingredient or were familiar with the trade names of the medication and used them to obtain the drugs to treat common ailments. $33 \%$ students used old prescriptions to procure over the counter medication whereas $12 \%$ consulted the pharmacist for obtaining these medicines (Figure 2).

The students were questioned regarding their knowledge of the dose of the over the counter drugs they were commonly 
using and their awareness of the dosage instructions. $73 \%$ of the students felt quite confident about their knowledge of correct dose and the dosage instructions. Rest $27 \%$ admitted that they were not aware of the exact dose and dosage instructions. $90 \%$ of the students were aware about the fact that these medications may cause adverse drug reactions (Figure 3).

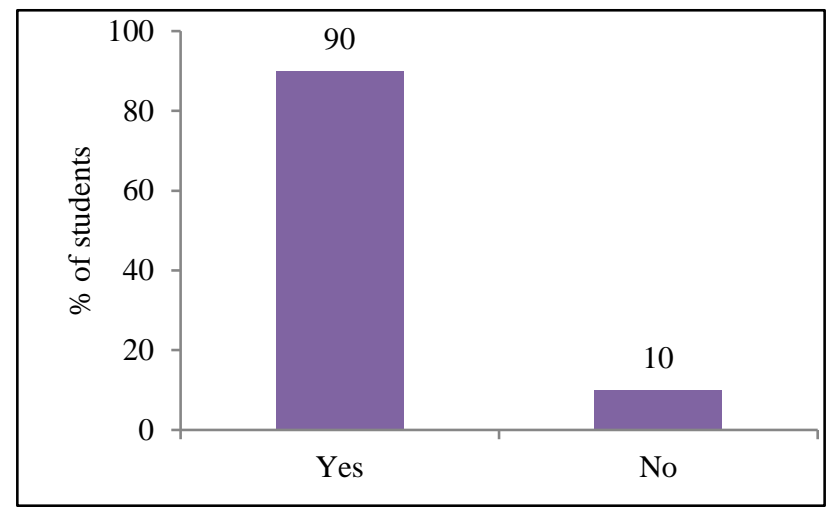

\section{Figure 3: Awareness regarding ADRS with} OTC drugs.

Only 5\% reported having experienced any ADR's like allergic reactions $(n=3)$, nausea and vomiting (4), sedation $(n=1)$, dizziness $(n=1)$ and palpitation $(n=1)$ with use of OTC drugs.

\section{DISCUSSION}

In present study the common indications for which the students used OTC medication included head ache, fever, cold, cough, abdominal pain, gastritis, diarrhea, vomiting and various allergic reactions. In other studies, conducted in different states of India involving $1^{\text {st }}$ and $2^{\text {nd }}$ year MBBS students, the indications of use were somewhat similar. ${ }^{8,9}$ Headache and body aches (74\%) followed by fever (72\%) were the most common indications making analgesics and antipyretics as one of the most commonly used OTC drugs. It is important to educate undergraduate students that OTC analgesics even though considered safe should be used cautiously for minimum possible duration and at lowest possible dose. ${ }^{10}$ In response to the question on the frequency of use of over the counter drugs most of the students responded that they used these drugs occasionally or once or twice a month. In this study authors did not come across students using OTC drugs chronically.

Most of the students (58\%) stated that they were confident that they were taking correct medicine for their ailment. This observation is reflective of the fact that medical education contributes to increased student awareness regarding various medicines and their indications. This might have lead to increased confidence amongst the students. A similar observation was made in another study carried out in undergraduate students in Kuwait university where they observed that medical knowledge gained from the medical study boosts the confidence of undergraduate students. ${ }^{11}$ But this attitude does predispose the students to chances of making wrong diagnosis, prolonging the illness and resulting in increased health cost. Thus, self medication may be deleterious to health. In our study $38 \%$ stated that the reason behind self medication is lack of time to visit a doctor and only a few (4\%) cited financial constraint as the reason for not seeking proper prescription from a doctor.

Since the study involved $2^{\text {nd }}$ year MBBS students most of them were aware of the trade names or constituent salts of the drugs $(55 \%)$. Very few students reported adverse drug reaction with commonly used OTC medications. In our study only 10 students reported any adverse drug reaction. These ADRs were nausea, vomiting, allergic reactions, sedation, dizziness and palpitations. In studies conducted in general population self medication with OTC drugs rarely leads to hospitalization. ${ }^{12}$

An important limitation of our study is comparison of the usage pattern with other sections of the society as well as hospital staff (nurses). Another important aspect could have been comparison of OTC drug consumption and pattern by rural and urban population.

Authors would like to follow up present study with sessions on awareness regarding OTC drug use. Periodic training and talks on self medication are necessary for MBBS students. It should always be emphasized that students should make it a habit to inquire about the use of over the counter drugs from their patients while taking history. Some of these OTC drugs can contribute to important drugdrug interactions. Student knowledge in this aspect will help them in future counseling of their patients.

\section{Funding: No funding sources}

Conflict of interest: None declared

Ethical approval: The study was approved by the Institutional Ethics Committee

\section{REFERENCES}

1. Brass EP. Changing the status of drugs from prescription to over the counter availability. N Engl J Med. 2001;345(11):810-6.

2. Neelima B. Over the counter drugs- Advantages and risks of self management of OTC drugs in older adult patients. J Bioanal Biomed 2014.6:2.

3. Wolf MS, King J, Jacobson K, Francesco LD, Bailey SC, Mullen R, et al. Risk of unintentional overdose with non prescription acetaminophen products. J Gen Intern Med. 2012 ;27(12):1587-93.

4. Porter G, Grills N. Medication misuse in India: a major public health issue in India. J Public Health. 2016;38(2):e150-7.

5. Virmani S, Nandigam M, Kapoor B, Makhija P, Nair S. Antibiotic use among health science students in an Indian university: A cross sectional study. Clin Epidemiol Global Health. 2017:176-9. 
6. Cook WB. Common adverse events and interactions with OTC pain medications. US Pharm. 2008;33(5):44-56.

7. Fontana RJ. Acute liver failure including Acetaminophen overdose. Med Clin North Am. 2008;92(4):761-94.

8. Rekha MS, Roopashree, Rekha MB, Naidu P. A study in the use of over the counter drugs among 1st year medical students in a tertiary care teaching hospital. Research \& reviews. J Pharmacol Toxicol Stud. 2015;3(1).

9. Reddy RV RN, Tar R, Senthil G, Priyadarshini. Self medication practices among II MBBS medical students in a tertiary care hospital- A cross sectional study. Pharma Innovation J. 2016;5(4):04-6

10. Moore N, Pollack C, Butkerati P. Adverse drug reactions and drug-drug interactions with over the counter NSAIDs. Ther Clin Risk Manag. 2015;15(11):1061-75.
11. Al Hussaini M, Mustafa S, Ali S. Self medication among undergraduate medical students in Kuwait with reference to the role of the pharmacist. J Res Pharm Pract. 2014;3(1):23-7.

12. Schmiedl S, Rottenkolber M, Hasford J, Rottenkolber D, Farker K, Drewelow B, et al. Self medication with over the counter and prescribed drugs causing adverse drug reactions related hospital admissions: Results of a prospective, long term multicentre study. Drug Saf. $2014 ; 37(4): 225-35$.

Cite this article as: Sood M, Bajaj JK, Grewal N. Evaluate use of over the counter drugs among medical students in a tertiary care teaching hospital. Int J Basic Clin Pharmacol 2019;8:973-6. 